\title{
FEATURES OF SPORTS PERFORMANCE RELATED INJURIES OF ELITE TRACK AND FIELD ATHLETES IN LITHUANIA
}

\author{
Linas Rekus, Lina Simaškaitė, Egidijus Šakalys \\ Lithuanian University of Health Sciences, Kaunas, Lithuania
}

\begin{abstract}
Background. Sports injuries have a huge impact on performance of athletes in competitions. A lot of athletes do not obtain full recovery after injuries, which leads to trauma recurrence or higher severity injuries. Being aware of dominating anatomical regions and frequencies of occurrence of these traumas could help to prevent it and to protect athletes' health.

Methods. In 2013 Lithuanian professional athletes were asked to fill in questionnaires developed by using standardized methodology validated by the IOC and implemented by the IAAF during international track and field competitions. Data were collected, processed and analysed. Results were obtained using statistical methods, significance level of $p \leq .05$ was considered statistically significant.

Results. We investigated 33 athletes- sprinters and throwers (javelin and discus throwers, shot putters). They had 57 cases of traumatic injuries in one year period (2012-2013). Results of the study showed that injuries of lower extremity statistically significantly dominated comparing with upper extremity and head/trunk in both fields of sport. Injuries by anatomical region were: lower extremity $-67 \%$, upper extremity $-12 \%$, head and trunk $-21 \%$. Most of all were injured: hamstrings 23\%, inguinal 10.5\%, lumbar 13\% area. Comparing traumas between throwers and sprinters groups lower extremity injuries statistically significantly dominated in sprinters group, while upper extremity had been injured only in the throwers' group. Analysing severity of the injuries we noticed that moderate and mild injuries were dominating. Mild and moderate severity injuries appeared leading to a higher risk of re-injury than high severity traumas. Recurrence of the same injury was noticed only in the group of sprinters $-57.9 \%$ of sprinters repeatedly suffered mostly from hamstring and inguinal traumas.

Conclusions. According to the results of this study, sports medicine physicians could predict potential localization and recurrence of injuries and collaborating with coaches and athletes prepare opportune training programs to avoid harm.
\end{abstract}

Keywords: sports injuries, recurring injuries, trauma, track and field athletics, sports medicine

\section{INTRODUCTION}

$\mathrm{T}$ Track and field (athletics) is a popular sport worldwide (Jacobsson et al., 2012). In today's society, sport is being widely accepted as integral part of keeping fit and retaining healthy lifestyle (D'Souza, 1994). Sports injuries have an important impact on sport and daily life (Edouard, Depiesse, Hertert, Branco, \& Alonso, 2013; Junge et al., 2009). To be able to plan safe sport (Alonso et al., 2009; Heiderscheit, Sherry, Silder, Chumanov, Thelen, 2010; Proske, Morgan,
Brockett, \& Percival, 2004) and to choose the best treatment and rehabilitation for athletes in track and field, injury patterns need to be registered (Hoskins\& Pollard, 2005; Lempainen, Sarimo, Mattila, Heikkilä, \& Oravaet, 2007; Owoeye, Odebiyi, Odunaiya, Ogunkunle, 2010). Additionally, there is sparse of research on injury rates, prevalence, type and severity affecting athletes of track and field (Huxley, O'Connor, Healey, 2013). So it is reasonable to analyse the most injured body parts/ 
localizations, recurrence of the same injury (Opar, Williams, \& Shield, 2012), chronic pain/unhealed, trauma/unhealed injury, severity degree, differences between sprinters and throwers. Many authors strive to examine severity of injuries (Rekus et al., 2013) and use diverse range of methodologies for its graduation (Malliaropoulos, Isinkaye, Tsitas, \& Maffulli, 2011). In this study we investigated Lithuanian elite sprinters and throwers (javelin and discus throwers, shot putters) trained in 2013. The objectives of this study was to analyse which body parts were mostly injured, to assess incidence of the severity of traumas and their connection with primary localization and to evaluate frequency of recurrences as well. These findings may be beneficial and give possibility to adjust training programs for track and field athletics.

\section{METHODS}

The objects of this study were Lithuanian elite track and field athletes in 2013. The questionnaire was given to sprinters and throwers (javelin and discus throwers, shot putters) in their training and competitive places. The study involved 33 athletes: $63.6 \%$ men $(n=21)$ and $36.4 \%$ women $(n=12)$, who potentially suffered from injuries over one year period (2012-2013). Their age ranged from 18 to 32 (mean of age was $21.64 \pm 0.58$ ) years. Median sports experience was $7.52 \pm 0.59$ years. Average of trainings sessions per week were $5.88 \pm 0.33$. Mean of one training session length was $108.18 \pm 2.90$ minutes. All 33 athletes participated in Lithuania's Track and Field championship in 2013. Ten athletes were included in the Olympic lists. We examined 14 throwers (javelin and discus throwers, shot putters) and 19 sprinters $(100 \mathrm{~m}, 200 \mathrm{~m}, 400 \mathrm{~m}, 4 \times 100 \mathrm{~m}$, $4 \times 400 \mathrm{~m}$, hurdles). There were 57 traumatic injury cases overall. The testing methodology was the same like in the other our study (Rekus et al., 2013), only minor changes and new questions about chronic pain/ trauma/unhealed injury were added.

Instruments. All 33 athletes were given a questionnaire which was made by standardized methodology (Daily Report on Injuries and Illnesses, codes and classifications) validated by the International Olympic Committee (IOC) and implemented by the International Association of Athletics Federations(IAAF) during international track and field competitions, during the period of the Daegu 2011 IAAF World Championships (27 August to 4 September). The Questionnaire was applied during trainings and competitions registering injuries of track and field athletics all year round in 2013. In our questionnaire there were 13 questions: 1 . Sex; 2. Age; 3 . Date of birth; 4. Number of training years in track and field; 5. Average time of training sessions per week; 6. Average length of training session; 7. Event; 8. Are you competing in Lithuanian track and field championship?; 9. Are you included in the Olympic lists?; 10. Number of injuries in 2013; 11. Point out injured body parts on the human silhouette picture (we classified body parts similarly to validated IOC and IAAF standardized classification): Head and trunk: a. face, b. head, c. neck, d. upper back, e. pectoral area, f. lumbar area, g. abdomen, j. pelvis/sacrum/gluteal area; Upper extremity: a. shoulder, b. elbow, c. forearm, d. wrist, e. hand, f. finger; Lower extremity: a. inguinal, b. quadriceps area, c. hamstrings area, d. popliteal area, e. knee area, f. calf, g. Achilles, h. ankle, i. foot; 12. Write/ grade your every injury severity by 5 degrees showed below: I. very mild injury (no missed training sessions); II. Mild injury (1 to 7 training days missed); III. Moderate injury (about 2 weeks training missed); IV. Severe injury (from 2 weeks up to 3 months training missed); V. Very severe injury (training stopped for 6 months and more); 13. Do you have chronic pain/ trauma/unhealed injury show anatomical region? Our questionnaire did not ask what kind of trauma it was and what its causes were as not all athletes who suffered very mild injuries had turned for medical care. That is why a questionnaire had been given not to physicians but to athletes themselves. We did not add questions about damaged structures and type of injury because not all athletes could remember the clinical diagnosis and approach terminology of medicine. We used the silhouette of the figure of the human body upon which an athlete pointed out the injured body parts (area of injury) and noted the time of impaired health, how many times they could not work out. By the number of missed training and competition days we made classification of the injury severity degree. We investigated how many and what kind of injuries the athlete had suffered as well as a recurrence of the same injury in 2013. As javelin, shot putters and discus throwers' training principles and some technical moments had much in common with each other, thus we combined them into one group called the "Throwers". Same was done with different sprint types: $100 \mathrm{~m}$, $200 \mathrm{~m}, 400 \mathrm{~m}, 4 \times 100 \mathrm{~m}, 4 \times 400 \mathrm{~m}$ and hurdles, and we named them the "Sprinters". Similar events categories were done in David D'Souza study 
(D’Souza, 1994). Due to this, we expected to have more accurate results.

Data analysis was performed using Statistical Package for Social sciences (SPSS) version 20. Data are reported as mean \pm standard error. Frequency between classified body parts was analysed by related samples Cochran's Q Test. Comparing groups of athletes with injuries and without injuries we used one-sample Binomial test. Injury cases between two different groups of events were compared by independent-samples Mann-Whitney $U$ test. Statistical significance was set at $p \leq .05$.

\section{RESULTS}

During the chosen period of study we examined 33 athletes: 14 throwers and 19 sprinters. Only 2 athletes (both in the throwers group) had no injuries. Statistically significantly more athletes experienced traumas $(p<.05)$. In the group of throwers 12 athletes had 18 injury cases, while two of them had no trauma. In the group of sprinters 19 athletes had 39 injuries. Overall 31 athletes experienced 57 injuries. There was no significant difference between incidences of injuries sustained by two groups - sprinters and throwers.

Localization of primary injury. There were 57 injury cases overall: head and trunk - $12(21 \%)$ : neck -1 (2\%), upper back $-2(3 \%)$, lumbar -8
(13\%), gluteal - 1 (2\%); upper extremity $-7(12 \%)$ : wrist $-1(2 \%)$, elbow $-1(2 \%)$ shoulder $-4(7 \%)$, fingers - $1(2 \%)$; lower extremity -38 (67\%): ankle$4(7 \%)$, Achilles $-3(5 \%)$, calf anterior $-2(3 \%)$, calf posterior $-1(2 \%)$, popliteal region $-2(3 \%)$, knee $-5(8 \%)$, inguinal - $6(10.5 \%)$, quadriceps -3 (5\%), hamstrings - 12 (23\%) (Table, Figure 1).

In both fields of sport the lower extremity injuries statistically significantly dominated comparing with upper extremity and head and trunk $(p<.05)$.

In the group of throwers there was no significant difference between lower extremity, upper extremity and head and trunk experienced injuries. The most injured parts of lower extremity were knee $-16.6 \%$, hamstrings $-11 \%$ and ankle $11 \%$. In upper extremity traumas shoulder area was dominating $-22 \%$ (Figure 2 ).

In the group of sprinters lower extremity injuries $(p<.05)$ were dominating comparing with others - upper extremity and head and trunk, injuries. Most damaged parts of lower extremity were hamstrings $-26 \%$, groins $-16 \%$ and quadriceps $-8 \%$. In localization of head and trunk, $18 \%$ of noted injuries were in lumbar area (Figure 3). Interestingly, sprinters have no injuries in the region of upper extremity.

Comparing lower extremity injuries in throwers' and sprinters' groups statistically
Table. Frequency of participants injuries by body region

Note. *Percent of these traumas in particular athlete group.

\begin{tabular}{|l|c|c|c|c|}
\hline & $\begin{array}{c}\text { Head and trunk } \\
\text { injuries } \\
(n=12)\end{array}$ & $\begin{array}{c}\text { Upper extremity } \\
\text { injuries } \\
(n=7)\end{array}$ & $\begin{array}{c}\text { Lower extremity } \\
\text { injuries } \\
(n=38)\end{array}$ & $\begin{array}{c}\text { Total } \\
(\boldsymbol{N}=\mathbf{5 7})\end{array}$ \\
\hline Sprinters & $9(23 \% *)$ & $0(0 \% *)$ & $30(77 \% *)$ & $39(68 \%)$ \\
\hline Throwers & $3(17 \% *)$ & $7(39 \% *)$ & $8(44 \% *)$ & $18(32 \%)$ \\
\hline
\end{tabular}

Figure. 1. All injuries (\%) 


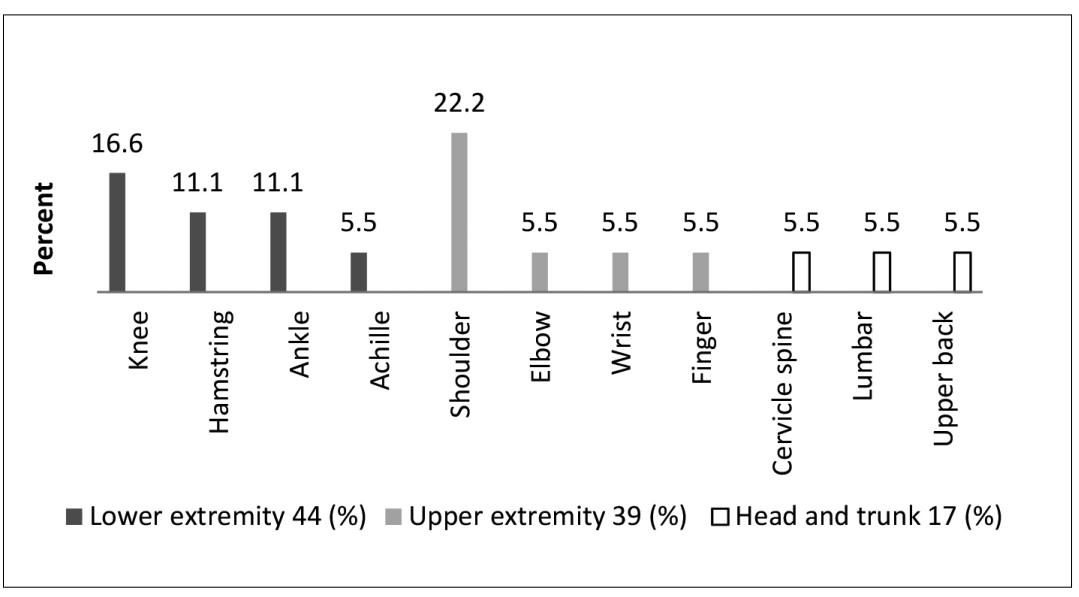

Figure 2. Injury places by body region and localization (total injuries of throwers)
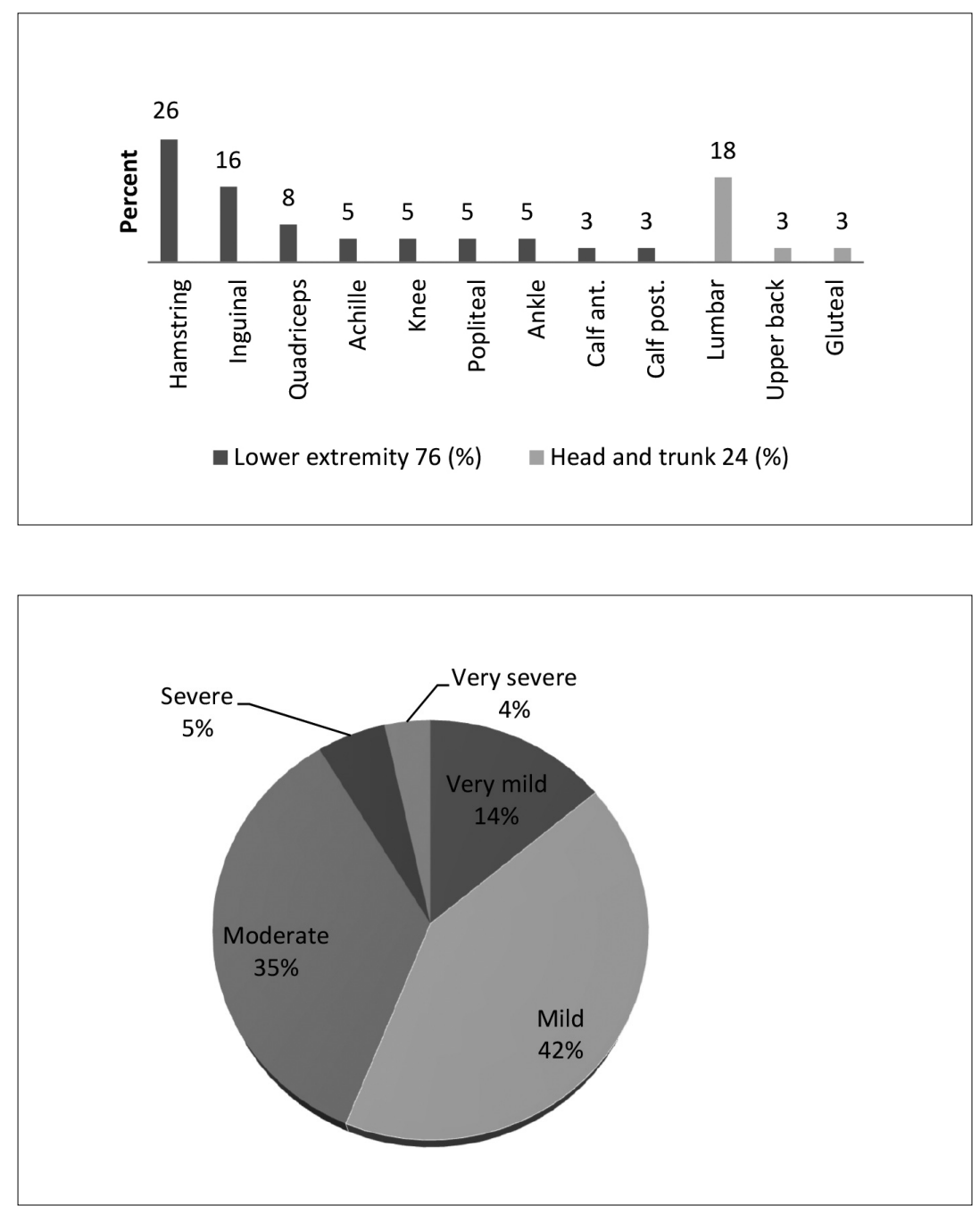

Figure 3. Injury places by body region and localization (total injuries of sprinters)

Note. Ant. - anterior, post. - posterior.

Figure 4. Distribution of injuries by degree of severity $(N=57)$ significantly $(p<.05)$ lower extremity injuries were dominating in sprinters group compared to throwers. Upper extremity had been injured only in throwers group.

Severity of injuries. Comparing the severity of the injuries, we established that moderate and mild injuries were dominating. Among 57 traumas, 42\% $(n=24)$ were mild, $35 \%(n=20)$ were moderate, $14 \%(n=8)$ very mild, $5 \%(n=3)$ severe and $4 \%$ $(n=2)$ very severe (Figure 4$)$.

By severity three most common injuries by localization distributed as follows:

1. Injuries of hamstrings: $67 \%$ mild, $25 \%$ moderate, $8 \%$ were very mild, while no severe and very severe injuries appeared; 
2. Traumas of lumbar localization were only mild (88\%) and moderate (12\%);

3. In inguinal area were $67 \%$ moderate, $16.5 \%$ mild and $16.5 \%$ severe traumas.

Recurrence of the same injury. Comparing repetition of injuries between group of throwers and sprinters there were established statistically reliable difference $(p<.05)$ : in the group of throwers there was no recurrence of the same during the study period, while in the group of sprinters 11 athletes had recurrence. It affirms that $57.9 \%$ of sprinters over one year period repeatedly suffered from injuries, which distributed as follows:

1. Injury of hamstrings relapsed for 3 sprinters, 2 of them had it more than once;

2. Inguinal/groin injuries relapsed for 3 athletes, 2 of them had it more than once as well;

3. Two athletes had recurrence of lumbar injuries, 1 of them had it 3 times;

4. Several athletes had recurrence of quadriceps, inguinal and Achilles injuries.

Additionally, during the survey 8 sprinters and 1 thrower noted that they continued training with unhealed injuries.

\section{DISCUSSION}

Although our group has previously published a similar study, the scientific literature on injury risk in track and field athletes is still scarce. The injury surveillance system proved again to be accepted by the team physicians all over the world including homeland. However, further efforts should be implemented in the future to improve data completeness and quality. To address the potential for prevention, the information on injury mechanism must be considered in a model that also considers internal and external risk factors that can modify injury risk. Other important thing is that sports physicians could correctly assess these results - they will be able to predict potential risk of injuries and they will be ready to provide the necessary assistance. However, knowing about most injured body parts and localizations, recurrences of same injury, distribution of severity degrees may also be very beneficial to predict and prevent athletes of traumas.

The International Olympic Committee recently recommended health evaluations to be routine in all elite sports (Ljungqvist, Jenoure, \& Engebretsen, 2009). Athletes in this study were categorized by fields of sport in two groups: throwers (discus, javelin, shot put) and sprinters (100-400 m, including hurdles) (Jacobsson et al., 2012). Seasonal variations in competition and practice schedules can affect measures of injury prevalence in track and field. Here, data collection was conducted during a period of year. One of the limitations of this study was the minor number of cases for such analysis, but still the results obtained during the study allow distinguishing the tendencies. A precise description on the inciting event is a key component to understand the causes of any particular injury type in a given sport (Bahr \& Krosshaug, 2005). After comparing gained data it is getting clearer that Lithuanian elite track and field athletes have similar difficulties as other elite track and field athletes from different countries. No difference between events categories was verified statistically (Opar et al., 2012).

Researchers (Beijsterveldt et al., 2013) who used similar questionnaire by investigating athletes of The European Youth Olympic Festival found that the knee (12.1\%), ankle (11.1\%) and thigh (10.6\%) were the three most commonly injured body parts. Analysing sprinters and throwers specifically, we established that lower limb was the most common site of injury. Mostly injured body localization was lower extremity in a lot of studies (Graff \& Birken, 2009; Jacobsson et al., 2012; Pastre, Filho, \& Monteiro, 2004; Watson \& DiMartino, 1987; Zemper, 2005). Hamstring injuries were the most commonly recorded injuries of lower extremity (Alonso et al., 2010; Alonso et al., 2012; Hoskins \& Pollard, 2005; Junge et al., 2009; Opar et al., 2012; Verrall, Slavotinek, Barnes, \& Fon, 2003). Sprinters in other research are mentioned as in the high risk of lower extremity, particularly hamstrings (Alonso et al., 2009; Alonso et al., 2010; Alonso et al., 2012; Van Gent et al., 2007;) and inguinal region traumas (Hiti, Stevens, Jamati, Garza, \& Matheson, 2011). Eccentric strength training of hamstrings muscles should be a part of and should be recommended as a key component in traumas prevention programs. Recent evidence suggests that the protocols of eccentric training have the ability to reduce hamstring injuries (Malliaropoulos, 2013).

Studies with throwers mostly recorded injuries of the lower extremity were the knee. A study of Swedish elite track and field athletes (Jacobsson et al., 2012) showed the highest injury prevalence was the knee and lower leg. Owoeye and researchers (Owoeye, Odunaiya, Akinbo, \& Odebiyi, 2009) concluded that exercise therapy was the most 
frequently used treatment in the lower limbs traumas. This should be considered as the lower extremity is mostly injured body part in all fields of athletes.

Most common injury from upper extremity was shoulder and it was noticed only in throwers' group. In precision we should to exclude and to analyse different throwing events damaged structures and its character (Illyes \& Kiss, 2005) comparing with throwing techniques. It could be assumed that a throw is the action we make when throwing a pebble into the sea, but in fact, the sequence of events and biomechanics of this are completely different from that straight arm throw of javelin throwing, the centrifugally induced velocity of hammer throwing, the explosive push of putting the shot and the spinning pull of the discus throw (Copeland, 1993). Although, in our study, injuries of upper extremity were not common, and we may predict that if they appeared, they were treated well and long enough, so there was no recurrence of traumas of this localization.

All track and field athletics coaches and other supervising specialists know that these two fields completely differ in the sense of physical preparation and competing. In throwing biomechanics synchronously work all body muscles starting-up from leg, rotational rising to pelvis and all explosively power going to shoulder and hand. For this reason the focus is on lumbar region strengthen during the training. It would be logical to consider that heavy weight-training exercises may lead to many injuries (Aggrawal, Kaur, Kumar, \& Mathuret, 1979), but the tendency of trunk and back injuries was not strong. In our study of head and trunk injuries, there was no significant difference between groups of sprinters and throwers.

Malliaropoulos with their research team noted that low-grade injuries lead to a higher risk of reinjury than high-grade traumas (Malliaropoulos et al., 2011). We found that 8 sprinters and 1 thrower had chronic / unhealed injuries (mostly severe and very severe) during period of study, while it is known that acute or chronic injury of any anatomical region can easily lead to repetitive trauma(McSweeney, Naraghi, Salonen, Theodoropoulos, \& White, 2012). Additional factors leading to chronicity can come from the first injury us such through modifications in the muscle tissue and possible adaptive changes in biomechanics and motor patterns of sporting movements (Croisier, 2004). In our study, recurrence of the same injury mostly were in hamstrings, inguinal or lumbar area, as other surveys, mentioned earlier, reveals as well.

\section{CONCLUSIONS}

During the chosen period of the study most of athletes experienced traumas $(p<.05)$ : 31 versus 2 who were not injured. The lower extremity was the most injured part of body of all fields athletes $(p<.05)$, though we did not notice any strong tendency that throwers injured the lower extremity or upper extremity or head and trunk more frequently. While in the group of sprinters, lower extremity injuries $(p<.05)$, mostly hamstrings, dominated comparing them with head and trunk injuries. Besides, they did not suffer from traumas of the upper limbs at all.

Mild (42\%) and moderate (35\%) injuries were dominating and this type of injury severity led to a higher risk of re-injury than higher severity traumas. Injuries of hamstrings and lumbar area were mostly mild severity ( 67 and $88 \%$ of them), while injuries of inguinal area were usually moderate (67\%).

Recurrence of the same injury was noticed only in the group of sprinters: $57.9 \%$ sprinters repeatedly suffered from injuries, commonly from repetitive hamstrings and inguinal traumas.

\section{REFERENCES}

Aggrawal, N. D., Kaur, R., Kumar, S., \& Mathur, D. N. (1979). A study of changes in the spine in weight lifters and other athletes. British Journal of Sports Medicine, 13, 58-61. doi: 10.1136/bjsm.13.2.58

Alonso, J., M., Junge A., Renström, P., Engebretsen, L., Mountjoy, M., \& Dvorak, J. (2009). Sports injuries surveillance during the 2007 IAAF World Athletics
Championships. Clinical Journal of Sport Medicine 19(1), 26-32. doi: 10.1097/JSM.0b013e318191c8e7

Alonso, J. M., Pascal, E., Fischetto, G., Adams, B., Depiesse, F., \& Mountjoy, M. (2012). Determination of future prevention strategies in elite track and field: analysis of Daegu 2011 IAAF Championships injuries and illnesses surveillance. British Journal 
of Sports Medicine, 46, 505-514. doi: 10.1136/ bjsports-2012-091008

Alonso, J. M., Tscholl, P. M., Engebretsen, L., Mountjoy, M., Dvorak, J., \& Junge, A. (2010). Occurrence of injuries and illnesses during the 2009 IAAF World Athletics Championships. British Journal of Sports Medicine, 44, 1100-1105. doi: 10.1136/bjsm.2010.078030

Bahr, R., \& Krosshaug, T. (2005). Understanding injury mechanisms: A key component of preventing injuries in sport: Review. British Journal of Sports Medicine, 39, 324-329. doi: 10.1136/bjsm.2005.018341

Beijsterveldt, M., Thijs, K. M., Backx, F. J. G., Steffen, K., Brozičević, V., \& Stubbe, J. H. (2013). Sports injuries and illnesses during the European Youth Olympic Festival 2013. British Journal of Sports Medicine, 49, 448-452. doi: 10.1136/bjsports-2014-094035

Heiderscheit, B. C., Sherry, M. A., Silder, A., Chumanov, E. S., \& Thelen, D. G. (2010). Hamstring Strain Injuries: Recommendations for Diagnosis, Rehabilitation, and Injury Prevention. The Journal of Orthopaedic and Sports Physical Therapy, 40(2), 6781. doi:10.2519/jospt.2010.3047

Copeland, S. (1993). Throwing injuries of the shoulder. British Journal of Sports Medicine, 27, 221-227. doi: 10.1136/bjsm.27.4.221

Croisier, J. L. (2004). Factors associated with recurrent hamstring injuries. Sports Medicine, 34, 681-695. doi: 10.2165/00007256-200434100-00005

D’Souza, D. (1994). Track and field athletics injuries a one-year survey. British Journal of Sports Medicine, 28(3), 197-202. doi: 10.1136/bjsm.28.3.197

Edouard, P., Depiesse, F., Hertert, P., Branco, P., \& Alonso, J. M. (2013). Injuries and illnesses during the 2011 Paris European Athletics Indoor Championships. Scandinavian Journal of Medicine \& Science in Sports, 23(4), 213-218. doi: 10.1111/sms.12027

Graff, K., \& Birken, N. (2009). Epidemiologie der Verletzungen in der Leichtathletik Teil 3. Sport Orthopadie Traumatologie 25,215-222. doi: 10.1016/j. orthtr.2008.12.007

Hiti, C. J., Stevens, K. J., Jamati, M. K.,Garza, D., \& Matheson, G. O. (2011). Athletic osteitis pubis, 41(5), 361-376. doi: 10.2165/11586820-000000000-00000.

Hoskins, W., \& Pollard, H. (2005). Hamstring injury management-Part 2: Treatment. Manual Therapy, 10(3), 180-190. doi: 10.1016/j.math.2005.05.001

Huxley, D. J., O'Connor, D., \& Healey, P. A. (2013). An examination of the training profiles and injuries in elite youth track and field athletes. European Journal of Sport Science, 19, 11-22. doi: 10.1080/17461391.2013.809153

Illyés, A., \& Kiss, R. M. (2005). Shoulder muscle activity during pushing, pulling, elevation and overhead throw. Journal of Electromyography and Kinesiology: Official Journal of the International Society of
Electrophysiological Kinesiology, 15(3), 282-289. doi: 10.1016/j.jelekin.2004.10.005

Jacobsson, J., Timpka, T., Kowalski, J., Nilsson, S., Ekberg, J., \& Renström, P. (2012). Prevalence of musculoskeletal injuries in Swedish elite track and field athletes. The American Journal of Sports Medicine, 40 (1), 163-169. doi: 10.1177/0363546511425467

Junge, A., Engebretsen, L., Mountjoy, M. L., Alonso, J. M., Renström, P. A., Aubry, M. J., \& Dvorak, J. (2009). Sports injuries during the Summer Olympic Games 2008. The American Journal of Sports Medicine, 37 (11), 2165-2172. doi: 10.1177/0363546509339357

Lempainen, L., Sarimo, J., Mattila, K., Heikkilä, J., \& Orava, S. (2007). Distal tears of the hamstring muscles: review of the literature and our results of surgical treatment. British Journal of Sports Medicine, 41, 8083. doi: 10.1136/bjsm.2006.031211

Ljungqvist, A., Jenoure, P., \& Engebretsen, L. (2009). The International Olympic Committee (IOC) Consensus Statement on periodic health evaluation of elite atheletes. British Journal of Sports Medicine, 43(9), 631-643. doi: 10.1136/bjsm.2009.064394

Malliaropoulos, N. G. (2013). Non-contact hamstring injuries in sports. Muscles Ligaments Tendons Journal, 2(4), 309-311.

Malliaropoulos, N., Isinkaye, T., Tsitas, K., \& Maffulli, N. (2011). Re-injury after acute posterior thigh muscle injuries in elite track and field athletes. The American Journal of Sports Medicine, 39(2), 304-310. doi: $10.1177 / 0363546510382857$

Mc Sweeney, S. E., Naraghi, A., Salonen, D., Theodoropoulos, J., \& White, L. M. (2012). Hip and groin pain in the professional athlete. Canadian Association of Radiologists Journal, 63(2), 87-99. doi: 10.1016/j.carj.2010.11.001

Opar, D. A., Williams, M. D., \& Shield, A. J. (2012). Hamstring strain injuries: Factors that lead to injury and re-injury. Sports Medicine. 42(3), 209-226. doi: 10.2165/11594800-000000000-00000

Owoeye, O. B. A., Odunaiya, N., Akinbo, S. R., \& Odebiyi, D. (2009). A retrospective study of sports injuries reported at the National Sports Medicine Centre, Lagos, South-West, Nigeria. The Internet Journal of Rheumatology 6(1), 11-23. Retrieved from http://ispub. com/IJRH/6/1/5092

Owoeye, O. B. A., Odebiyi, D. O., Odunaiya, N., Ogunkunle, E. (2010). Treatment of sports injuries referred for physiotherapy at a national sports medicine centre in Nigeria: A retrospective study. Nigerian quarterly Journal of Hospital Medicine, 19(3), 158-161. doi: 10.4314/nqjhm.v19i3.54504

Pastre, C. M., Filho, G. C., \& Monteiro, H. L. (2004). Sports injuries in track and field: Comparison between information obtained in medical records and reported morbidity inquires. Revista Brasileira de Medicina do 
Esporte, 10(1), 1-8. http://dx.doi.org/10.1590/S151786922004000100001

Proske, U., Morgan, D. L., Brockett, C. L., \& Percival, P. (2004). Identifying athletes at risk of hamstring strains and how to protect them. Clinical and Experimental Pharmacology and Physiology, 31(8), 546-50. doi: 10.1111/j.1440-1681.2004.04028.x

Rekus, L., Rekuvienè, E., Burkauskienė,A., Rekienè, D. E., Senikienè, Ž., Paršeliūnas, A., \& Šakalys, E. (2013). Peculiarities of sports injuries of sprint and throwing cohorts in track and field athletics. Education. Physical Training. Sport, 88, 2-8.

Van Gent, R. N., Siem, D., Van Middelkoop, M., Van Os, A. G., Bierma-Zeinstra, S. M. A., \& Koes, B. W. (2007). Incidence and determinants of lower extremity running injuries in long distance runners: A systematic review. British Journal of Sports Medicine, 41, 469480. doi: 10.1136/bjsm.2006.033548

Verrall, G. M., Slavotinek, J. P., Barnes, P. G., \& Fon, G. T. (2003). Diagnostic and prognostic value of clinical findings in 83 athletes with posterior thigh injury: Comparison of clinical findings with magnetic resonance imaging documentation of hamstring muscle strain. The American Journal of Sports Medicine, 31(6), 969-973.

Watson, M. D., \& DiMartino, P. P. (1987). Incidence of injuries in high school track and field athletes and its relation to performance ability. The American Journal of Sports Medicine, 15, 251-254.

Zemper, E. D. (2005). Track and field injuries. Medicine and Sport Science, 48, 138-151. doi: 10.1159/000084287 